\title{
Successive perioperative management of laparoscopic liver resection in the reverse Trendelenburg position for a patient with Fontan physiology: a case report
}

\author{
Kazutomo Saito ${ }^{1 *}$, Hiroaki Toyama ${ }^{1}$, Moeka Saito ${ }^{2}$ and Masanori Yamauchi ${ }^{1}$
}

\begin{abstract}
Background: Laparoscopic surgery for a patient with Fontan physiology is challenging because pneumoperitoneum and positive pressure ventilation could decrease venous return and the accumulated partial pressure of arterial carbon dioxide $\left(\mathrm{PaCO}_{2}\right)$ could increase pulmonary vascular resistance, which might lead to disruption of the hemodynamics.

Case presentation: A 25-year-old man with Fontan physiology was scheduled to undergo laparoscopic liver resection for Fontan-associated liver disease (FALD) with noninvasive monitoring of cardiac output (CO) by transpulmonary thermodilution in addition to transesophageal echocardiography. The abdominal air pressure was maintained low, and we planned to switch to open abdominal surgery promptly if hemodynamic instability became apparent because of the accumulated $\mathrm{PaCO}_{2}$ or postural change. Consequently, the pneumoperitoneum had limited influence on circulatory dynamics, but central venous pressure significantly decreased with postural change to the reverse Trendelenburg position. Laparoscopic liver resection for FALD was performed successfully with no significant changes in $\mathrm{CO}$ and central venous saturation.

Conclusions: With strict circulation management, laparoscopic surgery for a patient with Fontan physiology can be performed safely. Comprehensive hemodynamic assessment by noninvasive transpulmonary thermodilution can provide valuable information to determine the time for shift to open abdominal surgery.
\end{abstract}

Keywords: Laparoscopic liver resection, Reverse Trendelenburg position, Fontan-associated liver disease, Transpulmonary thermodilution

\section{Background}

Laparoscopic liver resection is usually performed in the reverse Trendelenburg position, which can induce a decrease in venous return from the lower extremity. The decreased preload can disrupt the hemodynamics of the Fontan circulation [1]. Because of $\mathrm{CO}_{2}$ insufflation and postural change, intraoperative management during

\footnotetext{
* Correspondence: kazutomo0815@gmail.com

'Anesthesiology and Perioperative Medicine, Tohoku University Graduate School of Medicine, 2-1 Seiryomachi, Aoba-ku, Sendai, Miyagi 980-8575, Japan

Full list of author information is available at the end of the article
}

laparoscopic liver resection after the Fontan procedure is not clearly described.

Meanwhile, open upper abdominal surgery is more invasive than laparoscopic surgery [2], and postoperative respiratory function of obese patients may worsen. Additionally, insufficient pain control and postoperative atelectasis, followed by hypoxia, can increase the pulmonary vascular resistance (PVR); therefore, minimally invasive surgery is preferable for obese patients with Fontan physiology.

In this report, we present the intraoperative management during laparoscopic liver resection for Fontan- 
associated liver disease (FALD) with noninvasive monitoring of cardiac output (CO) and transesophageal echocardiography.

\section{Case presentation}

The patient was a 25-year-old obese man (height, 159.8 $\mathrm{cm}$; body weight, $92.5 \mathrm{~kg}$ ). At birth, he was diagnosed with double-outlet right ventricle, pulmonary atresia, and atrioventricular septal defect after cyanosis and heart murmur were evident. He underwent a rightmodified Blalock-Taussig shunt at 34 days of age to increase the pulmonary blood flow. Cardiac catheterization indicated that the left ventricle was hypoplastic (left ventricular end-diastolic volume, $58 \%$ of normal), and pediatric cardiologists clarified the impossibility of biventricular repair. Therefore, he underwent the Glenn procedure at the age of 1 year and a fenestrated total cavopulmonary connection at the age of 3 years.

In this patient, the systemic ventricle was a morphologic right ventricle with a low ejection fraction, and the central venous pressure (CVP) was high at $16 \mathrm{mmHg}$; therefore, he was at a greater risk of hemodynamic instability.

At the age of 20 years, abdominal ultrasonography detected a large $(>6 \mathrm{~cm})$ tumor in segment 6 of the liver. Surgical treatment in Fontan-palliated patients is deemed unpredictable; therefore, he was treated nonsurgically. However, at 25 years, protein induced by vita$\mathrm{min} \mathrm{K}$ antagonist-II level increased to $336 \mathrm{mAU} / \mathrm{ml}$ (cutoff value, $40 \mathrm{mAU} / \mathrm{ml}$ ). Hepatocellular carcinoma was suspected; therefore, he was admitted to our hospital for surgical liver resection. On admission, the Child-Pugh class was determined as A. Blood hemoglobin was 17.3 $\mathrm{mg} / \mathrm{dl}$, platelet count was $21.3 \times 10^{4} / \mu \mathrm{l}$, and prothrombin time was $82.3 \%$. The liver function was well preserved. Preoperative echocardiography revealed that the right-ventricular ejection fraction was $34 \%$ with a limited atrioventricular valvular regurgitation; CVP was 16 $\mathrm{mmHg}$, saturation of peripheral oxygen $\left(\mathrm{SpO}_{2}\right)$ was $94 \%$ on room air at rest, and PVR was low $\left(1.0 \mathrm{WUm}^{2}\right)$.

It is difficult to determine whether laparoscopic surgery or open laparotomy procedure is more advantageous for a patient with Fontan physiology. Considerable preoperative discussions were conducted among the medical team members. In patients with Fontan physiology, adequate intravascular volume (preload) and low PVR should be maintained during the surgical procedure. During laparoscopic surgery, hypercarbia due to $\mathrm{CO}_{2}$ insufflation and high airway pressure caused by obesity could increase PVR. However, postoperative pain after open surgery could also increase PVR; therefore, we selected the less-invasive laparoscopic surgery for this Fontan-palliated patient. During pneumoperitoneum, this patient was scheduled to inhale nitric oxide, which dilates the pulmonary blood vessels selectively. Moreover, $\mathrm{CO}$ was measured continuously by transpulmonary thermodilution, such as a pulse contour cardiac output catheter (PiCCO; PULSION Medical Systems, Munich, Germany), in addition to transesophageal echography.

We planned to maintain low abdominal air pressure during pneumoperitoneum and to shift promptly to open abdominal surgery if hemodynamic instability became apparent because of the accumulated partial pressure of carbon dioxide $\left(\mathrm{PaCO}_{2}\right)$ or postural change.

In the operating room, the patient's electrocardiogram, $\mathrm{SpO}_{2}$, and noninvasive blood pressure (NIBP) were monitored. At baseline, NIBP was $132 / 88 \mathrm{mmHg}$, heart rate was $91 / \mathrm{min}$, and $\mathrm{SpO}_{2}$ was $93 \%$ under room air conditions. After insertion of epidural catheter, general anesthesia was induced by propofol $(90 \mathrm{mg})$, remifentanil $(0.2 \mu \mathrm{g} / \mathrm{kg} / \mathrm{min})$, and rocuronium $(100 \mathrm{mg})$. After orotracheal intubation, anesthesia was maintained by desflurane inhalation and fentanyl and remifentanil infusion. He received volume-controlled ventilation with fraction of inspired oxygen $\left(\mathrm{F}_{\mathrm{I}} \mathrm{O}_{2}\right)$ of 0.7 , positive endexpiratory pressure of $6 \mathrm{cmH}_{2} \mathrm{O}$, peak inspiratory pressure of less than or equal to $22 \mathrm{cmH}_{2} \mathrm{O}$, tidal volume of $450 \mathrm{ml}$, and respiratory rate of $15-18$ breaths $/ \mathrm{min}$. Minute ventilation was adjusted to maintain end-tidal $\mathrm{CO}_{2}$ $\left(\mathrm{EtCO}_{2}\right)$ at $30-35 \mathrm{mmHg}$.

With ultrasound guidance, $\mathrm{CO}$ and stroke volume variant were monitored via the PiCCO catheter. Then, a central venous catheter (PreSep Catheter ${ }^{\mathrm{TM}}$; Edwards Lifesciences, Irvine, CA, USA) was placed via the right internal jugular vein to monitor CVP and central venous saturation $\left(\mathrm{ScrO}_{2}\right)$ continuously. The tip of the central venous catheter was located just cephalad to the connection between the superior vena cava and the right pulmonary artery. Figure 1 shows the trend of the vital signs, including $\mathrm{CO}$, cardiac index (CI), CVP, $\mathrm{ScvO}_{2}$, and $\mathrm{EtCO}_{2}$ during anesthesia. Time 0 was defined as the start of general anesthesia. At baseline, $\mathrm{F}_{\mathrm{I}} \mathrm{O}_{2}$ was 0.7 , CI was $1.75 \mathrm{l} /$ $\mathrm{min} / \mathrm{m}^{2}, \mathrm{CVP}$ was $20 \mathrm{mmHg}$, and $\mathrm{ScvO}_{2}$ was $74 \%$.

After initiating pneumoperitoneum, arterial blood pressure (ABP) increased slightly, but $\mathrm{CO}$ and $\mathrm{ScvO}_{2}$ were invariant. After postural change to the reverse Trendelenburg position, CVP decreased from 17 to 13 $\mathrm{mmHg}$, but $\mathrm{CO}$ and $\mathrm{ScrO}_{2}$ remained unchanged. The insufflation pressure was maintained at $8-10 \mathrm{cmH}_{2} \mathrm{O}$. We administered an appropriate muscle relaxant for optimum surgical conditions. During pneumoperitoneum, the patient inhaled nitric oxide to decrease PVR. The Pringle maneuver during the liver resection did not affect CVP adversely. After withdrawal of the reverse Trendelenburg position, the CVP increased rapidly from 14 to $24 \mathrm{mmHg}$, but decreased subsequently to 20 mmHg. Nevertheless, $\mathrm{CO}$ and $\mathrm{ScvO}_{2}$ remained stable. CI and $\mathrm{CO}$ were stable at low levels, and laparoscopic 


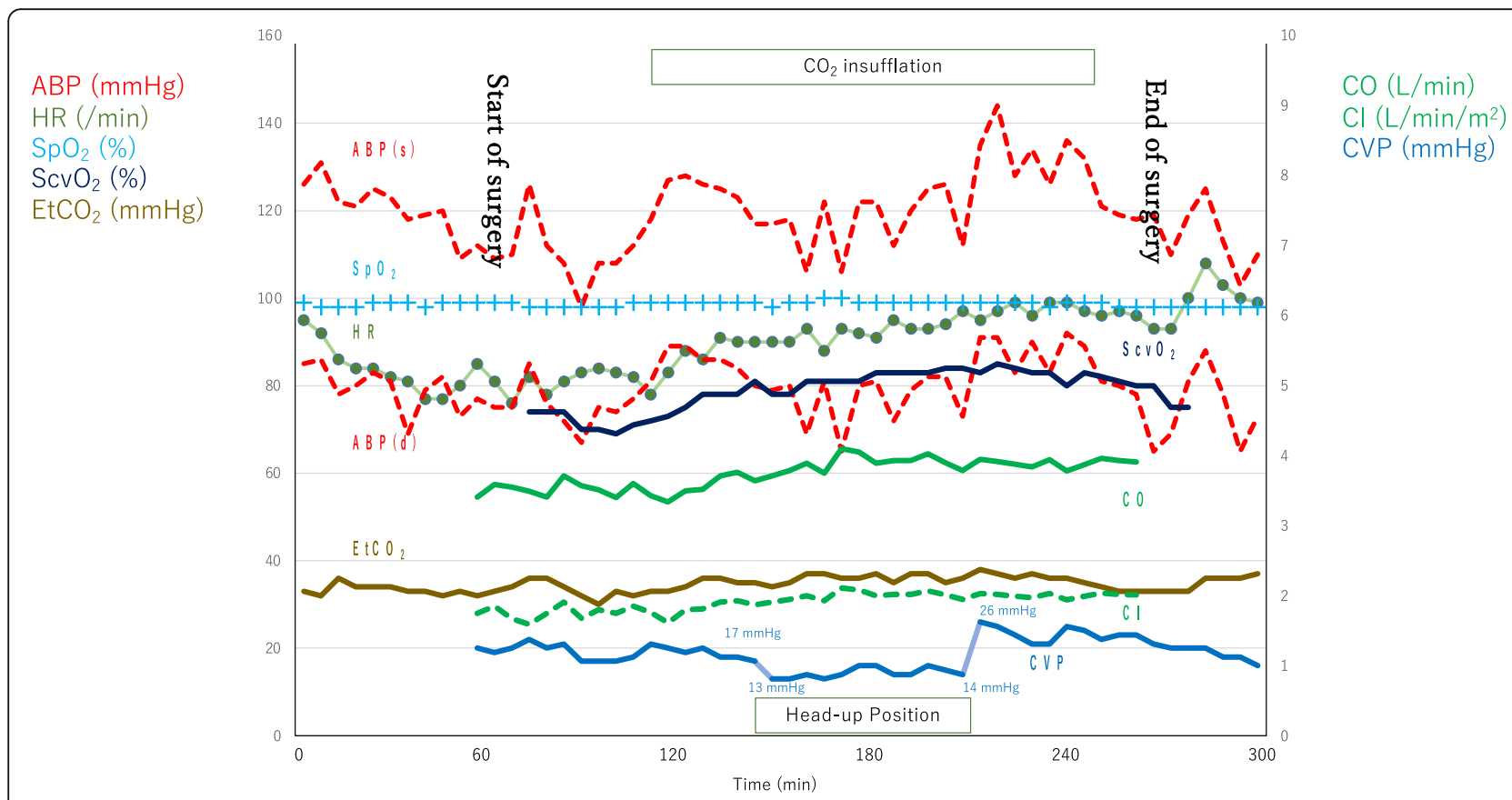

Fig. 1 Trends of hemodynamic parameters during anesthesia. ABP, arterial blood pressure; $\mathrm{HR}$, heart rate; $\mathrm{SpO}_{2}$, saturation of peripheral oxygen; $\mathrm{ScvO}_{2}$, central venous saturation; $\mathrm{EtCO}_{2}$, end-tidal $\mathrm{CO}_{2} ; \mathrm{CO}$, cardiac output; $\mathrm{Cl}$, cardiac index; $\mathrm{CVP}$, central venous pressure

partial hepatectomy was concluded successfully with hemodynamic stability. Transesophageal echography revealed no remarkable changes. Blood loss and urine output were $295 \mathrm{ml}$ and $158 \mathrm{ml}$, respectively, which were replaced with $2200 \mathrm{ml}$ of crystalloid.

After reversal of neuromuscular blockade, the patient was extubated and admitted to the intensive care unit. Postoperative analgesia using levobupivacaine and fentanyl was successfully administered via an epidural catheter. He remained hemodynamically stable and was shifted to the general ward on the 1st postoperative day. He was discharged on the 8 th postoperative day with no postoperative complications. The resected liver mass was pathologically diagnosed as focal nodular hyperplasia with no malignancy.

\section{Discussion}

With the improvement in surgical techniques and perioperative management, adult patients with postoperative congenital heart disease are increasing, and they frequently require non-cardiac surgery. In Fontan physiology, a single ventricle bears the systemic and pulmonary circulation and requires higher CVP to drive the pulmonary circulation. In addition, Fontan-palliated patients are less tolerant of volume overload. Therefore, perioperative management of the post-Fontan population is challenging.

Hepatic complications related to the congestive liver caused by a high CVP are called FALD [3]. FALD consists of liver fibrosis, cirrhosis, and adenoma; focal nodular hyperplasia; and hepatocellular carcinoma [4]. FALD is associated with congestive liver and low CO [5].

The treatment of choice for FALD between laparoscopic and open abdominal surgery is often difficult to determine. In laparoscopic surgery, increased abdominal pressure caused by pneumoperitoneum can decrease venous return from the inferior vena cava. Moreover, the increased intrathoracic pressure induced by positive pressure ventilation and elevated $\mathrm{PaCO}_{2}$ can increase PVR. Therefore, laparoscopic surgery is considered disadvantageous in Fontan-palliated patients. Several reports have discussed laparoscopic surgery for a patient with Fontan physiology [6, 7].

However, laparoscopic surgery is less invasive than open abdominal surgery and is associated with lesser postoperative pain [2]. As inadequate pain control could increase PVR, a less-invasive approach such as laparoscopic hepatectomy is preferred. In this case, because the patient was obese (body mass index, $36.2 \mathrm{~kg} / \mathrm{m}^{2}$ ), laparoscopic surgery had a limited effect on postoperative respiratory function, and hence, we anticipated an early recovery from surgical stress.

In this case, we chose laparoscopic surgery for FALD with strict hemodynamic management, including $\mathrm{CO}$ and $\mathrm{ScvO}_{2}$ sequential monitoring. ABP increased with $\mathrm{CO}_{2}$ insufflation, but $\mathrm{CO}, \mathrm{ScvO}_{2}$, and $\mathrm{CVP}$ remained stable. After postural change to the reverse Trendelenburg position, CVP decreased. Nevertheless, $\mathrm{CO}$ and $\mathrm{ScvO}_{2}$ were not significantly affected by body position. 
In this Fontan-palliated patient, the postural change affected only the CVP, and the pneumoperitoneum did not influence the hemodynamic status directly. This might be due to the low intra-abdominal pressure, maintained at $8-10 \mathrm{cmH}_{2} \mathrm{O}$ [7]. If circulatory dynamics become unstable because of pneumoperitoneum or postural change, we should promptly switch to open abdominal surgery.

In regard to respiratory management in this Fontanpalliated patient, we administered PEEP to prevent the exacerbation of oxygenation. Although PEEP could reduce pulmonary blood flow, hypoxia could also increase PVR and subsequently decrease pulmonary blood flow. As this patient was obese, we adopted the use of PEEP to prevent atelectasis during mechanical ventilation. Additionally, this patient inhaled NO to decrease PVR during pneumoperitoneum. In this case, the pulmonary blood flow was not monitored and so we did not correctly understand the effect of NO inhalation. However, the patient inhaled $\mathrm{NO}$ during pneumoperitoneum, and hemodynamic parameters, such as $\mathrm{ScvO}_{2}$ or CI, did not change during surgical procedures. We consider that NO could suppress the increase of PVR induced by pneumoperitoneum.

The head-up position is considered disadvantageous for Fontan-palliated patients owing to the inhibited venous return, but advantageous for laparoscopic liver resection to achieve a good surgical field. In this case, CVP decreased with postural change to the reverse Trendelenburg position. However, no changes in $\mathrm{CO}$ or $\mathrm{ScvO}_{2}$ were observed. We guess that during the reverse Trendelenburg position the intrathoracic pressure could decrease and increase pulmonary blood flow. The effect of $\mathrm{NO}$ is not clear, but $\mathrm{NO}$ could dilate the pulmonary blood vessel.

Management of low CVP during liver resection can decrease blood loss $[8,9]$. The intraoperative blood loss in this case was $295 \mathrm{ml}$. The CVP reduction induced by the head-up position may have contributed to the limited bleeding. Massive blood loss could be fatal for Fontan-palliated patients, in whom adequate preload is necessary to sustain the pulmonary blood flow. If the head-up position does not affect hemodynamic parameters, it can be advantageous for laparoscopic hepatectomy in a patient with Fontan physiology. Compared to the head-down position, the intrathoracic pressure does not increase and has less impact on PVR. Increased pneumoperitoneal pressure can also control bleeding. If the pneumoperitoneal pressure exceeds the hepatic venous pressure, the oozing blood loss could decrease.

We must pay attention to the pharmacokinetics of anesthetic agents in patients with Fontan circulation. Many of Fontan-palliated people suffer from deterioration in liver function. We anesthesiologists must be careful in the administration of agents which are metabolized largely in the liver.

Consequently, laparoscopic liver resection was successfully performed in this case, with no hemodynamic complications. The patient was extubated in the operating room and shifted to the intensive care unit. Postoperative pain control was completed by epidural anesthesia. Although the patient was obese, he was discharged from the hospital on the 8th postoperative day with no respiratory complications.

\section{Conclusions}

In the perioperative management of FALD, $\mathrm{CO}_{2}$ insufflation had a limited effect on hemodynamics. With strict circulation management using noninvasive monitoring systems such as the PiCCO catheter, laparoscopic surgery for a patient with Fontan physiology can be performed safely. Postural change to the reverse Trendelenburg position can decrease CVP, which could contribute to reduced blood loss. If postural change or $\mathrm{CO}_{2}$ insufflation affects hemodynamic status, open liver resection should be performed. Comprehensive hemodynamic assessment by noninvasive transpulmonary thermodilution in addition to myocardial motion monitoring by transesophageal echography can provide valuable information for determining the time of shift to open abdominal surgery.

\section{Abbreviations}

ABP: Arterial blood pressure; $\mathrm{PaCO}_{2}$ : Partial pressure of arterial carbon dioxide; PVR: Pulmonary vascular resistance; CVP: Central venous pressure; FALD: Fontan-associated liver disease; $\mathrm{CO}$ : Cardiac output; $\mathrm{ScvO}_{2}$ : Central venous saturation; $\mathrm{SpO}_{2}$ : Saturation of peripheral oxygen; $\mathrm{EtCO}_{2}$ : End-tidal $\mathrm{CO}_{2} ; \mathrm{Cl}$ : Cardiac index; NIBP: Noninvasive blood pressure; $\mathrm{F}_{1} \mathrm{O}_{2}$ : Fraction of inspired oxygen

\section{Acknowledgements}

Not applicable.

\section{Authors' contributions}

KS was the primary anesthetist and drafted the manuscript. HT and MS supervised anesthetic management. HT and MY drafted the manuscript. All authors have read and approved the final manuscript.

\section{Authors' information}

$\mathrm{KS}, \mathrm{MD}, \mathrm{PhD}$, Assistant Professor of Anesthesiology and Perioperative Medicine, Tohoku University School of Medicine; HT, MD, PhD, Associate Professor of Anesthesiology and Perioperative Medicine, Tohoku University School of Medicine; MS is MD and a Clinical Fellow of Department of Anesthesiology, Tohoku University Hospital; MY, MD, PhD, Professor of Anesthesiology and Perioperative Medicine, Tohoku University School of Medicine.

\section{Funding}

Not applicable

\section{Availability of data and materials}

The datasets used and/or analyzed during the current study are available from the corresponding author upon reasonable request.

\section{Declarations}

Ethics approval and consent to participate Not applicable. 


\section{Consent for publication}

Written informed consent was obtained from the patient for publication of this case report and accompanying images.

\section{Competing interests}

The authors declare that they have no competing interests.

\section{Author details}

'Anesthesiology and Perioperative Medicine, Tohoku University Graduate School of Medicine, 2-1 Seiryomachi, Aoba-ku, Sendai, Miyagi 980-8575, Japan. ${ }^{2}$ Department of Anesthesiology, Tohoku University Hospital, 1-1

Seiryomachi, Aoba-ku, Sendai, Miyagi 980-8575, Japan.

Received: 24 May 2021 Revised: 22 June 2021

Accepted: 23 June 2021 Published online: 13 July 2021

References

1. Yokota Y, Kobayashi Y, Matsumoto K, Sakano Y, Imagami Y, et al. A case report of Fontan procedure-related hepatocellular carcinoma: pure laparoscopic approach by low and stable pneumoperitoneum. BMC Surg. 2020;20(1):80. https://doi.org/10.1186/s12893-020-00741-8.

2. Wakabayashi G, Cherqui D, Geller DA, Buell JF, Kaneko H, Han HS, et al. Recommendations for laparoscopic liver resection: a report from the second international consensus conference held in Morioka. Ann Surg. 2015;261(4): 619-29. https://doi.org/10.1097/SLA.0000000000001184.

3. Rychik J, Veldtman G, Rand E, Russo P, Rome JJ, Krok K, et al. The precarious state of the liver after a Fontan operation: summary of a multidisciplinary symposium. Pediatr Cardiol. 2012;33(7):1001-12. https://doi.org/10.1007/ s00246-012-0315-7.

4. Schwartz MC, Sullivan L, Cohen MS, Russo P, John AS, Guo R, et al. Hepatic pathology may develop before the Fontan operation in children with functional single ventricle: an autopsy study. J Thorac Cardiovasc Surg. 2012; 143(4):904-9. https://doi.org/10.1016/j.jtcvs.2011.08.038.

5. Baek JS, Bae EJ, Ko JS, Kim GB, Kwon BS, Lee SY, et al. Late hepatic complications after Fontan operation; non-invasive markers of hepatic fibrosis and risk factors. Heart. 2010;96(21):1750-5. https://doi.org/10.1136/ hrt.2010.201772.

6. Taylor KL, Holtby H, Macpherson B. Laparoscopic surgery in the pediatric patient post Fontan procedure. Paediatr Anaesth. 2006;16(5):591-5. https:// doi.org/10.1111/j.1460-9592.2005.01826.x.

7. McClain CD, McGowan FX, Kovatsis PG. Laparoscopic surgery in a patient with Fontan physiology. Anesth Analg. 2006;103(4):856-8. https://doi.org/1 0.1213/01.ane.0000237294.88298.8e.

8. Hughes MJ, Ventham NT, Harrison EM, Wigmore SJ. Central venous pressure and liver resection: a systematic review and meta-analysis. HPB (Oxford). 2015;17(10):863-71. https://doi.org/10.1111/hpb.12462.

9. Wang F, Sun D, Zhang N, Chen Z. The efficacy and safety of controlled low central venous pressure for liver resection: a systematic review and metaanalysis. Gland Surg. 2020;9:311-20.

\section{Publisher's Note}

Springer Nature remains neutral with regard to jurisdictional claims in published maps and institutional affiliations.

\section{Submit your manuscript to a SpringerOpen ${ }^{\circ}$ journal and benefit from:}

- Convenient online submission

- Rigorous peer review

- Open access: articles freely available online

- High visibility within the field

- Retaining the copyright to your article

Submit your next manuscript at $\boldsymbol{\nabla}$ springeropen.com 